\title{
Do transposed-letter effects occur across lexeme boundaries?
}

\author{
MANUEL PEREA \\ Universitat de València, Valencia, Spain \\ and \\ MANUEL CARREIRAS \\ Universidad de La Laguna, Tenerife, Spain
}

\begin{abstract}
A masked priming lexical decision experiment was conducted to examine whether or not assignment of letter position in a word can be influenced by lexeme boundaries. The experiment was run in Basque, which is a strongly agglutinating language with a high proportion of inflected and compound words. Nonword primes were created by transposing two nonadjacent letters that crossed or did not cross morphological boundaries. Specifically, we compared morphologically complex prime-target pairs (e.g., arbigide-ARGIBIDE) with orthographic controls (e.g., arkipide-ARGIBIDE; note that ARGIBIDE is a compound of ARGI + BIDE) and noncompound pairs (e.g., ortakila-ORKATILA) with orthographic controls (e.g., orbahila-ORKATILA). Results showed that transposed-letter effects were virtually the same for compound and noncompound words, both when the orthographic control condition was used as a baseline and when the identity condition was used as a baseline. Thus, transposed-letter similarity effects seem to be orthographic in nature. We examine the implications of these results for the models of visual word recognition.
\end{abstract}

Two key issues in the literature on visual word recognition are (1) how internal letters are coded in the right positions within a word (i.e., how we distinguish between anagrams such as causal and casual) and (2) the role that is played by morphology in early orthographic processing (e.g., whether or not readers "decompose" compound words during the process of lexical access). To shed some light on these questions, we examined whether assignment of letter positions in a word can be influenced by lexeme boundaries.

In recent years, a growing body of data has shown that transposing two internal letters of a monomorphemic word results in perceptually similar "neighbors" (e.g., trial-trail, jugde-judge), which leads to an increased level of difficulty in word recognition tasks. In masked priming experiments, transposed-letter nonword primes produce not only form-priming effects relative to the appropriate orthographic control (e.g., jugde-JUDGE vs. jupte-JUDGE; Perea \& Lupker, 2003b, 2004a; see also Andrews, 1996;

The research reported in this article was partially supported by Grants SEJ2004-07680-C02-02/PSIC and SEJ2005-05205/EDU from the Spanish Ministry of Education and Science and Grant BFF2002-10379-E from the ESF-EUROCORES-OMLL. We thank Max Coltheart, Michael Cortese, and an anonymous reviewer for helpful criticism of an earlier draft. Thanks are also due Edurne Laseka for selecting the stimuli and conducting the experiment. Correspondence concerning this article should be addressed to M. Perea, Departament de Metodologia, Facultat de Psicologia, Av. Blasco Ibáñez, 21, 46010-València, Spain (e-mail: mperea@uv.es).
Forster, Davis, Schoknecht, \& Carter, 1987; Schoonbaert \& Grainger, 2004), but also associative priming effects (e.g., jugde-COURT vs. ocaen-COURT; Perea \& Lupker, 2003a). (Note that these effects have also been obtained within the context of normal silent reading using parafoveal previews; see Johnson, Perea, \& Rayner, 2005.) Furthermore, transposed-letter effects also occur when the transposed letters are not adjacent (e.g., caniso-CASINO vs. caviro-CASINO; Perea \& Carreiras, 2006; Perea \& Lupker, 2004a).

The ubiquity of transposed-letter similarity effects in reading rules out the "position-specific" coding schemes that have been employed in most computational models of visual word recognition (e.g., the interactive activation model of McClelland \& Rumelhart, 1981, and its extensions: the dual-route cascaded model of Coltheart, Rastle, Perry, Langdon, \& Ziegler, 2001, and the multiple read-out model of Grainger \& Jacobs, 1996). For this reason, new input coding schemes have recently been proposed that successfully capture transposed-letter similarity effects (e.g., the SOLAR model of Davis, 1999; the overlap model of Gómez, Perea, \& Ratcliff, 2003; the SERIOL model of Whitney, 2001). Interestingly, these models assume that transposed-letter similarity effects have a very early locus, probably at an orthographic level of representation. (We defer a more detailed treatment of this issue to the Discussion.)

The question we ask in the present study is whether morphological boundaries affect the magnitude of transposedletter effects. Prior research on transposed-letter effects focused on monomorphemic words. Recent evidence with 
the masked priming technique suggests that morphological decomposition may operate early in the processing of orthographic representations (see Rastle, Davis, \& New, 2004). Specifically, Rastle et al. found significant masked priming effects whenever primes and targets appeared to be morphologically related, independently of whether the pairs were semantically related (e.g., cleaner-CLEAN, $27 \mathrm{msec}$ ) or not (e.g., corner-CORN, $22 \mathrm{msec}$ ). These effects were greater than the priming effects observed when primes and targets had a nonmorphological relationship (e.g., brothel-BROTH, $4 \mathrm{msec}$; note that $\mathrm{el}$ is not a suffix in English). Rastle et al. argued that these findings "implicate a level of representation, accessed in early visual word recognition, at which morphological decomposition is defined on a purely orthographic basis, where words are segmented simply because they have a morphological structure (e.g., corner)" (p. 1095). If, as argued by Rastle et al. (see also Christianson, Johnson, \& Rayner, 2005; Longtin, Segui, $\&$ Halle, 2003), the morphological decomposition process occurs very early in processing (i.e., if compound words would be decomposed early in processing), one would expect the magnitude of transposed-letter effects across lexemes in compound words (e.g., dealdine-DEADLINE vs. deatbine-DEADLINE) to be smaller than that of transposedletter effects in noncompound words (e.g., funtcionFUNCTION vs. funlrion-FUNCTION). In this light, Christianson et al. (2005) indicated that readers may be "more sensitive to letter transpositions across morpheme boundaries than they are to transpositions within morphemes, despite the fact that both types of transpositions occur string internally" (p. 1336). (Bear in mind that transposed-letter effects with noncompound words tend to diminish when the transposition of letters involves the exterior letters; see Chambers, 1979; Perea \& Lupker, 2003a, 2004b.) That is, if assignment to letter position within a compound word is to some degree separate for each lexeme, one would expect a smaller transposed-letter effect when the transposition of letters affects both of the compound's lexemes. In contrast, if this letter assignment process occurs very early in processing, before morphological decomposition takes place (as is assumed in the SOLAR model of Davis, 1999, and in the overlap model of Gómez et al., 2003), then transposed-letter priming effects should be equivalent for compound and noncompound words.

The experiment was run in Basque. Basque is an ancient, pre-Indo-European language spoken at the western end of the Pyrenees, close to the Spanish-French border. Morphology in Basque is strongly agglutinating (e.g., etxe, "house"; etxea, "the house"; etxeak, the houses"; etxean, "in the house"; etxera, "to the house"; etxetik, "from the house"; etxezaina, "butler"; etxelaguna, "housemate"; etxetxoria, "sparrow"; etxejabe, "house owner"). Thus, Basque is an excellent language with which to examine whether or not words are decomposed in the process of lexical access. Evidence that Basque readers decompose compound words into their component units has recently been reported by Laseka, Perea, and Carreiras (2005). Laseka et al. found that the frequency of the second lexeme had a facilitative influence for low-frequency compounds. This finding builds upon previous results in English (see Juhasz, Starr, Inhoff, \& Placke, 2003), in which a word frequency effect was found for the whole compound.

In the present experiment, we opted to transpose two nonadjacent (consonant) letters rather than two adjacent letters. The reason is that transposing two adjacent letters in a word tends to produce irregular and/or low-frequency bigrams (e.g., "gd" in the transposed-letter nonword jugde) and also tends to alter the word's syllabic structure (e.g., jugde vs. JUDGE). Keep in mind that transposing two nonadjacent consonants produces a robust masked priming effect relative to appropriate orthographic controls (with two letters changed; see, e.g., Perea \& Lupker, 2004a; see also Perea \& Carreiras, 2006).

In sum, to examine the involvement of morphology in transposed-letter similarity effects, we compared morphologically complex pairs (e.g., arbigide-ARGIBIDE) with their orthographic controls (e.g., arkipide-ARGIBIDE; note that ARGIBIDE is a compound of ARGI + BIDE) and noncompound pairs (e.g., ortakila-ORKATILA) with orthographic controls (e.g., orbahila-ORKATILA) in a masked priming lexical decision task, using a $47-\mathrm{msec}$ stimulus onset asynchrony (SOA). In a recent masked priming naming study with a $100-\mathrm{msec}$ SOA, Christianson et al. (2005) failed to find a differential transposed-letter effect for noncompound and compound words using replacement-letter primes as the appropriate control (the difference between sacrasm-SARCASM and sansasmSARCASM was $34 \mathrm{msec}$, and the difference between aiprortAIRPORT and aignort-AIRPORT was $43 \mathrm{msec}$ ). However, Christianson et al. found a greater difference between the identity condition and the transposed-letter condition for compound words $(43 \mathrm{msec})$ than for noncompound words $(6 \mathrm{msec})$. To test this possibility, we also included an identity priming condition (e.g., argibide-ARGIBIDE, orkatila-ORKATILA) in the experiment.

\section{METHOD}

\section{Participants}

Thirty-three students from the University of the Basque Country and the University of Deusto in Bilbao each received $€ 4$ for participating in the experiment. All of them had normal or corrected-tonormal vision and were native speakers of Basque.

\section{Materials}

The targets were 84 Basque words of seven to eight letters. Fortytwo of the words were noncompounds (e.g., ORKATILA, "ankle"). Their mean frequency per million words (Urkia, 2004) is 14.1 (range, 1-68.75), and their mean Coltheart's $N=0.9$ (range, $0-3$ ). The other 42 were compound words (e.g., ARGIBIDE, "explanation," a compound of ARGI + BIDE); their mean frequency per million words (Urkia, 2004) is 11.1 (range, 1-148.5), and their mean Coltheart's $N=0.2$ (range, $0-2$ ). The targets were presented in uppercase letters and preceded by lowercase primes that were (1) the same as the target (identity condition; e.g., orkatila-ORKATILA, argibideARGIBIDE), (2) the same as the target except for a transposition of two nonadjacent interior consonants (transposed-letter condition; e.g., ortakila-ORKATILA, arbigide-ARGIBIDE - note that for the compound words the transposition always involved letters from different 
morphemes), or (3) the same as in the transposed-letter condition except that the transposed letters were instead replaced by other consonants (replacement-letter condition; e.g., orbahila-ORKATILA, arkipide-ARGIBIDE). The transposed-letter and replacement-letter primes were always nonwords. The mean log bigram frequencies were similar for the transposed-letter and replacement-letter primes in the Basque database (Perea et al., in press).

An additional set of 84 orthographically legal nonwords (e.g., USBATILA, LOZAGEME) of seven to eight letters was included for the lexical decision task. Half of these nonwords had been created by replacing two letters from compound words (one letter in each lexeme), and the other half had been created by replacing two letters from noncompound words (one in the initial part of the word and one in the final part of the word, to parallel the structure of the compound-derived nonwords). The manipulation of the nonword trials was the same as that for the word trials (e.g., the prime-target pairs for the nonword target LOZAGEME would be lozageme-LOZAGEME for the identity condition, logazeme-LOZAGEME for the transposedletter condition, and lopameme-LOZAGEME for the replacementletter condition). Three lists of materials were constructed in such a way that each target appeared once in each list, each time in a different priming condition. Different groups of participants were used for each list.

\section{Procedure}

The participants were tested in groups of 2 in a quiet room. Presentation of the stimuli and recording of response times (RTs) were controlled by PC-compatible computers. The experiment was run using DMDX (Forster \& Forster, 2003). RTs were measured from target onset until the participant responded. On each trial, a forward mask consisting of a row of hash marks (\#s) was presented for $500 \mathrm{msec}$ in the center of the CRT monitor screen. Next, the prime was presented in lowercase in 12-point Courier and remained on the screen for $47 \mathrm{msec}$ (four 11.8-msec cycles). The prime was followed immediately by the presentation of the target stimulus in uppercase letters. Both prime and target were presented at the same screen location as the forward mask. The target remained on the screen until the participants responded. The participants were instructed to press one of two keys on the keyboard to indicate whether the uppercase letter string was a legitimate Basque word or not (" $m$ " for yes and " $z$ " for no). The participants were instructed to make this decision as quickly and as accurately as possible. They were not informed of the presence of lowercase items. Each participant received a different order of trials. Prior to presentation of the 168 experimental trials, each participant received 24 practice trials (with the same manipulation as the experimental trials). The whole session lasted approximately $12 \mathrm{~min}$.

\section{RESULTS}

Incorrect responses (9.6\% of the data for word targets) and RTs shorter than 250 or longer than $1,800 \mathrm{msec}$ (less than $1.0 \%$ of the data for word targets) were excluded from the latency analysis. The mean latencies for correct responses and error rates are presented in Table 1. Participant and item ANOVAs of latencies and percentage errors were conducted on the basis of a 2 (target: noncompound vs. compound) $\times 3$ (prime-target relationship: identity vs. transposition vs. replacement) $\times 3$ (list) design. List was included as a dummy variable to extract the variance due to the error associated with the lists. All significant effects had $p$ values less than .05 .

\section{Word Data}

The ANOVA on the RT data showed a main effect only of prime-target relatedness $\left[F_{1}(2,60)=11.81, M S_{\mathrm{e}}=\right.$ $\left.3,977.7 ; F_{2}(2,156)=10.97, M S_{\mathrm{e}}=5,553.7\right]$, which did not differ across noncompound and compound words (the $F$ ratios of the target $\times$ prime-target relatedness interaction were less than 1; see Table 1). A closer inspection of the data showed that the transposed-letter condition effect was significant in comparison with the replacementletter condition effect $\left[F_{1}(1,30)=6.05, M S_{\mathrm{e}}=4,141.1\right.$; $\left.F_{2}(1,78)=4.38, M S_{\mathrm{e}}=5,796.4\right]$, whereas there were no signs of a prime-target relatedness $\times$ target interaction (both $F_{\mathrm{s}}<1$; note that the effect was remarkably similar for noncompound [31 $\mathrm{msec}$ ] and compound [28 $\mathrm{msec}]$ words). With respect to the difference between the identity and the transposed-letter conditions, the effect was significant $\left[F_{1}(1,30)=5.71, M S_{\mathrm{e}}=2,876.4 ; F_{2}(1,78)=\right.$ $\left.6.25, M S_{\mathrm{e}}=5,734.5\right]$, and, again, there were no signs of an interaction between relatedness and target (both $F \mathrm{~s}<$ $1)$. The effect was the same for the noncompound and the compound words $(21 \mathrm{msec})$.

The ANOVA on the error data revealed only that responses to the noncompound words were less accurate than those to the compound words, although this effect occurred only in the subjects analysis $\left[F_{1}(1,30)=13.39\right.$, $\left.M S_{\mathrm{e}}=57.60 ; F_{2}(1,78)=1.47, M S_{\mathrm{e}}=626.2, p>.15\right]$.

Table 1

Mean Lexical Decision Times (RTs, in Milliseconds) and Percentages of Errors (\%Error) for Word and Nonword Targets Priming Condition

\begin{tabular}{|c|c|c|c|c|c|c|c|c|c|c|}
\hline & & \multirow{2}{*}{\multicolumn{2}{|c|}{ TL - Identity }} & \multirow{2}{*}{\multicolumn{2}{|c|}{$\mathrm{RL}-\mathrm{TL}$}} \\
\hline & \multicolumn{2}{|c|}{ Identity } & \multicolumn{2}{|c|}{$\mathrm{TL}$} & \multicolumn{2}{|c|}{$\mathrm{RL}$} & & & & \\
\hline & RT & $\%$ Error & RT & $\%$ Error & RT & $\%$ Error & RT & $\%$ Error & $\mathrm{RT}$ & $\%$ Error \\
\hline \multicolumn{11}{|c|}{ Word Trials } \\
\hline Noncompounds & 769 & 10.8 & 790 & 11.0 & 821 & 13.4 & 21 & 0.2 & 31 & 2.4 \\
\hline Compounds & 762 & 6.9 & 783 & 9.0 & 811 & 6.9 & 21 & 3.1 & 28 & -2.1 \\
\hline \multicolumn{11}{|c|}{ Nonword Trials } \\
\hline Noncompounds & 907 & 4.3 & 903 & 4.3 & 918 & 4.1 & -4 & 0.0 & 15 & -0.2 \\
\hline Compounds & 948 & 5.0 & 971 & 4.1 & 962 & 3.5 & 23 & -0.9 & -9 & -0.6 \\
\hline
\end{tabular}

Note-TL, transposed-letter condition; RL, replacement-letter condition. TL - Identity reflects the difference between the transposed-letter condition and the identity condition. $R L-T L$ reflects the difference between the replacement-letter condition and the transposed-letter condition. 


\section{Nonword Data}

The ANOVA on the RT data showed that the compoundderived nonwords had longer latencies than the nonwords not derived from compounds $\left[F_{1}(1,30)=37.36, M S_{\mathrm{e}}=\right.$ $\left.3,386.8 ; F_{2}(1,78)=10.78, M S_{\mathrm{e}}=14,527.6\right]$. Neither the main effect of relationship nor the interaction between target and relationship approached significance (both $F_{\mathrm{s}}<$ $1)$. The ANOVA on the error rates did not reveal any significant effects (all $F_{\mathrm{s}}<1$ ).

\section{DISCUSSION}

The central finding of the present experiment is clearcut: Transposed-letter similarity effects are unaffected by a word's morphological boundaries. The magnitude of the transposed-letter effect was virtually the same whether it occurred across or within morpheme boundaries. More specifically, when the appropriate orthographic control was used as the baseline, the transposed-letter effect across lexeme boundaries for compound words $(28 \mathrm{msec})$ was similar to the transposed-letter effect with noncompound words $(31 \mathrm{msec})$. Furthermore, when the identity condition was used as a baseline, the transposed-letter effect for compound and noncompound words was exactly the same (21 msec in both cases). We must keep in mind that the lack of an effect of morphology in the transposedletter condition does not preclude the important role of morphology in lexical access; as was stated in the introduction, there is clear evidence that the frequency of the constituents affects the speed of lexical access (see Laseka et al., 2005, for evidence in Basque). ${ }^{1}$

Taken together, these results are consistent with the common view that transposed-letter similarity effects have a very early locus, probably at an orthographic level of representation (Davis, 1999; Gómez et al., 2003). For instance, in the overlap model (Gómez et al., 2003), the assumption is made that orthographic representations extend beyond their specific letter positions into neighboring letter positions. The encoding activation of a given letter at a specific letter position is represented as a normal distribution with the peak of the curve falling at the correct letter position. The distribution, however, extends into other letter positions. Since this encoding of letter position is noisy, the letter "s" in the word causal is encoded at the fourth letter position as well as at adjacent locations, although to a lesser degree. In the current version of the model (Gómez et al., 2003), this distribution is purely orthographic and would not depend on whether the word is a compound or not. Thus, the model would predict a similar pattern of transposed-letter effects for compound and noncompound words. In the SOLAR model (Davis, 1999), letter assignment uses a spatial coding scheme. The transposed-letter words trial and trail would activate the same set of letter nodes and, therefore, they are perceptually similar. Readers are able to distinguish between trial and trail because the letter strings produce different activation patterns across the letter nodes according to their spatial locations within the letter string. The first letter of the string is coded by the highest activity, and all subsequent letters within the string are coded with progressively lower activities. The difference in the spatial coding of the two words trial and trail, then, leads to successive differentiation. This letter assignment process is posited to occur very early in processing, before morphological decomposition takes place, so that the SOLAR model correctly predicts that transposed-letter effects are not affected by morphological boundaries. Note that in the SOLAR model, decomposition of any morphologically complex word is carried out only after at least one of the constituent morphemes is recognized in the lexicon (Davis, 1999).

Thus, the present data suggest that assignment of letters to positions seems to be orthographically based and occurs mainly in a bottom-up manner. The reason why morphology did not have an effect in the present experiment is that morphological decomposition of a compound word may take place only after the constituent morphemes are recognized in the mental lexicon. Given that in the present experiment there were no obvious cues that marked the morpheme boundary (unlike languages such as Finnish, in which readers may use vowel harmony as a cue; see Bertram, Pollatsek, \& Hyönä, 2004), the cognitive system had no means of knowing where the morpheme boundaries were located. If our view is correct, then the locus of transposed-letter effects is purely orthographic and the ortho-morphological decomposition suggested by Rastle et al. (2004) would act over the (cascaded) output of this stage. With respect to the potential discrepancies between the present experiment and Christianson et al.'s (2005, Experiment 2) study, what we should note is that the SOA in their experiment was not too brief $(100 \mathrm{msec}$; in the present experiment, the SOA was $47 \mathrm{msec}$ ) and that the subjects' task was naming (rather than lexical decision). In Christianson et al.'s Experiment 2, when the appropriate orthographic controls were used as the baseline, the interaction between compound and noncompound words was not significant (priming effects of $31 \mathrm{msec}$ for compound words and $43 \mathrm{msec}$ for noncompound words, similar to the effects in the present experiment). When the identity condition was used as a baseline, the critical interaction was also not reported as significant, although a post hoc analysis showed a difference between the identity condition and the transposed-letter condition for compound (33 $\mathrm{msec})$ but not for noncompound $(6 \mathrm{msec})$ words. Thus, we believe that the evidence from Christianson et al. is not conclusive.

In sum, the present findings provide new constraints for the development of computational models of visual word recognition. The data strongly suggest that the way the brain codes the ordering of the letters within a word is determined at an orthographic level that precedes the influence of morphology, and this is consistent with the predictions of the SOLAR model (Davis, 1999) and the overlap model (Gómez et al., 2003). Thus, the most parsimonious explanation is that transposed-letter similarity effects are orthographic in nature. 


\section{REFERENCES}

ANDREWs, S. (1996). Lexical retrieval and selection processes: Effects of transposed-letter confusability. Journal of Memory \& Language, 35, 775-800.

Bertram, R., Pollatsek, A., \& Hyönä, J. (2004). Morphological parsing and the use of segmentation cues in reading Finnish compounds. Journal of Memory \& Language, 51, 325-345.

Chambers, S. M. (1979). Letter and order information in lexical access. Journal of Verbal Learning \& Verbal Behavior, 18, 225-241.

Christianson, K., Johnson, R. L., \& RaYner, K. (2005). Letter transpositions within and across morphemes. Journal of Experimental Psychology: Learning, Memory, \& Cognition, 31, 1327-1339.

Coltheart, M., Rastle, K., Perry, C., Langdon, R., \& Ziegler, J. (2001). DRC: A dual-route cascaded model of visual word recognition and reading aloud. Psychological Review, 108, 204-256.

DAVIS, C. J. (1999). The self-organising lexical acquisition and recognition (SOLAR) model of visual word recognition. Unpublished doctoral dissertation, University of New South Wales, Sydney, Australia.

Forster, K. I., Davis, C., Schoknecht, C., \& Carter, R. (1987). Masked priming with graphemically related forms: Repetition or partial activation? Quarterly Journal of Experimental Psychology, 39, 211-251.

Forster, K. I., \& Forster, J. C. (2003). DMDX: A Windows display program with millisecond accuracy. Behavior Research Methods, Instruments, \& Computers, 35, 116-124.

Gómez, P., Perea, M., \& Ratcliff, R. (2003, November). The overlap model of the encoding of letter positions. Poster presented at the 44th Annual Meeting of the Psychonomic Society, Vancouver, BC.

Grainger, J., \& Jacobs, A. M. (1996). Orthographic processing in visual word recognition: A multiple read-out model. Psychological Review, 103, 518-565.

Johnson, R. L., Perea, M., \& Rayner, K. (2005). Transposed-letter effects in reading: Evidence from eye movements and parafoveal preview. Manuscript submitted for publication.

Juhasz, B. J., Stark, M. S., Inhoff, A.W., \& Placke, L. (2003). The effects of morphology on the processing of compound words: Evidence from naming, lexical decisions and eye fixations. British Journal of Psychology, 94, 223-244.

Laseka, E., Perea, M., \& Carreiras, M. (2005, April). Processing compound words in Basque. Paper presented at the Seventh Symposium of Psycholinguistics, Valencia, Spain.

Longtin, C. M., Segui, J., \& Halle, P. (2003). Morphological priming without morphological relationship. Language \& Cognitive Processes, 18, 313-334.

McClelland, J. L., \& Rumelhart, D. E. (1981). An interactive activation model of context effects in letter perception: Part 1. An account of basic findings. Psychological Review, 88, 375-407.

Perea, M., \& Carreiras, M. (2006). Do transposed-letter similarity effects occur at a prelexical phonological level? Quarterly Journal of Experimental Psychology, 59, 1600-1613.
Perea, M., \& Lupker, S. J. (2003a). Does jugde activate COURT? Transposed-letter similarity effects in masked associative priming. Memory \& Cognition, 31, 829-841.

Perea, M., \& LupKer, S. J. (2003b). Transposed-letter confusability effects in masked form priming. In S. Kinoshita \& S. J. Lupker (Eds.), Masked priming: State of the art (pp. 97-120). Hove, U.K.: Psychology Press.

Perea, M., \& Lupker, S. J. (2004a). Can CANISO activate CASINO? Transposed-letter similarity effects with nonadjacent letter positions. Journal of Memory \& Language, 51, 231-246.

Perea, M., \& LuPKER, S. J. (2004b, November). The effect of transposed letter stimuli in visual word recognition. Paper presented at the 45th Annual Meeting of the Psychonomic Society, Minneapolis.

Perea, M., Urkia, M., Davis, C., Aguirre, A., Laseka, E., \& Carreiras, M. (in press). E-Hitz: A word-frequency list and a program for deriving psycholinguistic statistics in an agglutinative language (Basque). Behavior Research Methods.

Rastle, K., Davis, M. H., \& New, B. (2004). The broth in my brother's brothel: Morpho-orthographic segmentation in visual word recognition. Psychonomic Bulletin \& Review, 11, 1090-1098.

Schoonbaert, S., \& Grainger, J. (2004). Letter position coding in printed word perception: Effects of repeated and transposed letters. Language \& Cognitive Processes, 19, 333-367.

URKIA, M. (2004). Euskararen maiztasun hiztegia [Word frequency dictionary in Basque]. UZEI: Donostia.

Whitney, C. (2001). How the brain encodes the order of letters in a printed word: The SERIOL model and selective literature review. Psychonomic Bulletin \& Review, 8, 221-243.

\section{NOTE}

1. As Michael Cortese pointed out, it may be of interest to examine the role of the frequency of the lexemes for compound words. If the ordering of the letters precedes morphological decomposition, then one should find the transposition-letter effect to remain constant across the priming conditions. However, if the ordering of letters occurs at the same time as morphological decomposition, one may find that it interacts with the frequency of the lexemes. To test this possibility, we conducted a post hoc regression analysis on the magnitude of the transposed-letter effects for the compound words using the frequency of the first lexeme and that of the second lexeme as predictors. The results failed to show a significant relationship between the magnitude of the transposed-letter effect and the frequency of the first or second lexeme (all $p s>.30$ ). Thus, this analysis suggests that transposed-letter priming effects arise at a very early stage of the reading process - although caution is always warranted in the interpretation of a post hoc result.

(Manuscript received June 2, 2005; revision accepted for publication October 31, 2005.) 